\title{
Hubungan Tingkat Pengetahuan Penderita Hipertensi Tentang Penyakit Hipertensi Dengan Kepatuhan Regimen Terapeutik Di Kelurahan Lirboyo Rw 03 Dan 08 Kota Kediri
}

\author{
Puguh Santoso \\ Akper Dharma Husada Kediri
}

\begin{abstract}
In the prevention of complications of hypertension motivated by three factors: predisposing factors include knowledge, attitudes, beliefs, values, family traditions, contributing factors include the availability of source facilities, predisposing factors include attitudes, behaviors of health workers, family and friends. Knowledge or cognition is the dominant factor is very important to person's behavior to obey with the therapeutic regimen. Methods: This study design using analytical observation, while the population in this study are patients with hypertension who are in the Urban Village Lirboyo RW 03 and 08 of Kediri. Sample studies using total sampling, which amounted to 21 respondents. Questionnaires given to obtain in-depth information about the level of knowledge and compliance in hypertensive patients undergoing therapeutic regimen. Results, level of knowledge about hypertension hypertensive patients almost all respondents (71\%) good knowledge, few respondents knowledgeable enough (29\%). Therapeutic regimen compliance majority of respondents $(76 \%)$ adherence to the therapeutic regimen, a small portion of respondents (24\%) are less adherent to the therapeutic regimen. Results of the research necessary to increase knowledge and necessary also social support, resources, attitudes, behaviors, and motivations of people with hypertension to improve compliance in implementing the therapeutic regimen.
\end{abstract}

Keywords: Knowledge Level, compliance

\section{Pendahuluan}

Penyakit hipertensi atau tekanan darah tinggi merupakan tekanan darah persisten dimana tekanan sistoliknya diatas $140 \mathrm{mmHg}$ dan tekanan diastoliknya diatas $90 \mathrm{mmHg}$ (Dalimartha, 2008). Apabila hipertensi tetap tidak diketahui dan tidak dirawat akan mengakibatkan kematian ( Brunner dan Suddart, 2010: 897 ).

Penderita hipertensi di Amerika yang diobati sebanyak $59 \%$ dan yang terkontrol $34 \%$ sedangkan dinegara Eropa penderita yang diobati hanya sebesar $27 \%$ dan dari jumlah tersebut $70 \%$ tidak terkontrol. Penderita hipertensi di Indonesia diperkirakan sebesar 15 juta penduduk Indonesia yang kontrol hanya 4\%. (www.health.kompas.com) baik dipuskesmas maupun dirumah sakit terdapat $50 \%$ penderita hipertensi tidak menyadari dirinya sebagai penderita hipertensi. Terdiri dari $70 \%$ adalah hipertensi ringan dan $90 \%$ hipertensi esensial, hipertensi yang tidak diketahui penyebabnya dilaporkan yang teratur kontrol sebanyak 22,8 \% sedangkan yang tidak teratur kontrol sebanyak 77,2 \%, dari pasien hipertensi dengan riwayat kontrol tidak teratur tekanan darah yang belum terkontrol $91,7 \%$ sedangkan yang mengaku kontrol teratur dalam tiga bulan terakhir mudah dilaporkan $100 \%$ masih mengidap penyakit hipertensi (Dewi $\mathrm{T}$, 2013)

Prevalensi hipertensi secara nasional mencapai $31,7 \%$. Pada kelompok umur 25-34 tahun sebesar 7\% naik menjadi $16 \%$ pada kelompok umur 35-44 tahun dan kelompok umur 65 tahun atau lebih menjadi 29\% (Survey Kesehatan Nasional, 2007 dalam Eka 2011: 3)

Kediri merupakan salah satu kota yang memiliki tingkat hipertensi tinggi diJawa Timur yaitu sebesar 38.626 jiwayang menyebar di sembilan puskesmas yang berada di Kota Kediri setelah Kota Pasuruan, Probolinggo dan 
Madiun yang mana hipertensi merupakan faktor dominan terhadap kejadian stroke. Hal ini diketahui berdasarkan data dari Dinas Kesehatan Jawa Timur yang menunjukkan jumlah angka hipertensi di Jawa Timur mencapai 275.000 jiwa yang mana memiliki faktor resiko strok.

Dalam pencegahan komplikasi hipertensi dilatar belakangi oleh tiga faktor yaitu faktor predisposisi meliputi pengetahuan, sikap, kepercayaan, nilai, tradisi keluarga, faktor pendukung meliputi ketersediaan sumber fasilitas, faktor pendorong meliputi sikap, perilaku petugas kesehatan, anggota keluarga dan teman dekat(Agrina,2011). Pengetahuan atau kognitif merupakan faktor dominan yang sangat penting dalam membentuk tindakan seseorang (Ekarini, 2011). Perilaku yang didasari oleh pengetahuan akan lebih langgeng daripada perilaku yang tidak didasari oleh pengetahuan (Notoatmodjo, 2007: 144)

Penelitian Mardiyati (2009), menunjukkan bahwa penderita hipertensi mempunyai sikap yang buruk dalam menjalani diet hipertensi hal tersebut disebabkan oleh faktor pengetahuan penderita hipertensi. Sikap merupakan suatu tindakan aktivitas, akan tetapi merupakan predisposisi dari perilaku. Menurut Notoatmodjo (2007: 145), Perilaku seseorang adalah penyebab utama menimbulkan masalah kesehatan,tetapi juga merupakan kunci utama pemecahan. Perilaku merupakan faktor kedua terjadi perubahan derajat kesehatan masyarakat (Wawan, 2011). Jadi kepatuhan dapat ditingkatkan jika jika petugas kesehatan menjelaskan kepada pasien mengenai nilai hasil pengobatan dan menjelaskan bahwa mengikuti anjuran akan mendapatkan hasil baik dan jika pasien mengetahui serta menyadari sistem pengobatan, kenyakinan pasien, perasaan dan kebiasaan pasien akan meningkat dalam mematuhi regimen dan meningkatkan perilaku mematuhi ( Kaplan dan Saddock: 2001).
Berdasarkan hasil obeservasi, dari berbagai kegiatan yang dilakukan, antusias masyarakat (penderita hipertensi) yang menjadi target program. Hal ini dapat disimpulkan dari jumlah kehadiran para penderita hipertensi pada kegiatan posyandu lansia di kelurahan Lirboyo diikuti 11-17 orang, pada kegiatan senam sehat penderita hipertensi hadir 10 -12 peserta. Bulan Februari 2015 yang lalu peneliti melakukan pendataan dikelurahan Lirboyo RW 03 dan RW 08 memiliki kasus hipertensi tertinggi yaitu 70\% dari penderita di Kelurahan Lirboyo ,warga yang didata merupakan penderita hipertensi dan 5\% diantaranya terkena komplikasi jantung dan stroke. Berdasarkan studi pendahuluan kepada 12 warga RW 03 Lirboyo pada bulan Pebruari 2015 didapatkan hasil bahwa sembilan orang diantaranya tahu apa itu hipertensi tapi mereka sendiri tidak mengetahui penyebab, komplikasi dan cara penurunan faktor resiko hipertensi seperti apa. Untuk menurunkan angka komplikasi dan kematian akibat hipertensi, maka pengetahuan tentang hipertensi di RW 03 dan 08 di Kelurahan Lirboyo penting diteliti sebagai dasar menetapkan intervensi untuk penderita hipertensi di RW 03 dan 08 di Kelurahan Lirboyo Kota Kediri sehingga tidak menimbulkan komplikasi lain ataupun kematian.

\section{Metode Penelitian}

Penelitian ini dimulai pada bulan Pebruari sampai bulan Maret 2015. Penelitian ini menggunakan desain penelitian cross sectional yaitu penelitian observasional analitik yang dilakukan dan diamati dalam satu waktu (Nasehudin \& Nanang 2012).

Sedangkan populasi dalam penelitian ini adalah penderita hipertensi yang berada di Wilayah Kelurahan Lirboyo RW 03 dan 08 Kota Kediri. Penelitian ini menggunakan Total sampling. (Notoatmojo, 2005:89), yang berjumlah 21 responden. 
Variabel independent dalam penelitian ini adalah pengetahuan penderita hipertensi tentang penyakit hipertensi (X), sedangkan variabel dependentnya adalah adalah kepatuhan regimen terapeutik. (Y). Instrumen yang dipakai dalam penelitian ini adalah Kuesioner Pengetahuan tentang Hipertensi. Kuesioner ini berisi 15 pertanyaan dengan penjelasan pengertian, penyebab, tanda dan gejala, komplikasi, pencegahan, dan diet. Kuesioner ini menjelaskan tiga kategori yaitu baik, cukup, kurang (Wawan \& Dewi 2011). Kuesioner tentang Kepatuhan Diet Hipertensi berisi 10 pertanyaan dengan jawaban sangat sering, sering, kadangkadang, tidak pernah.

Pada penelitian ini untuk menguji hubungan tingkat pengetahuan penderita tentang Hipertensi terhadap Kepatuhan Diet Hipertensi digunakan uji regresi linier. Pengolahan perhitungan tersebut menggunakan bantuan program SPSS versi 17.

\section{Hasil Dan Pembahasan}

Karakteristik variabel disajikan pada tabel berikut:

Tabel 1. Tingkat pengetahuan

\begin{tabular}{llll}
\hline No. & $\begin{array}{l}\text { Tingkat } \\
\text { pengetahuan }\end{array}$ & F & P \\
\hline 1 & Baik & 15 & $71 \%$ \\
2 & Cukup baik & 6 & $29 \%$ \\
\hline & Jumlah & 21 & $100 \%$ \\
\hline
\end{tabular}

Sumber : Data Primer Tahun 2015

Berdasarkan hasil penelitian menunjukkan bahwa hampir seluruh responden $(71 \%)$ memiliki Tingkat pengetahuan dalam kategori baik.

Tabel 2. Tingkat Kepatuhan

\begin{tabular}{llll}
\hline No. & Katogori & F & P \\
\hline 1 & Patuh & 16 & $76 \%$ \\
2 & Kurang Patuh & 5 & $24 \%$ \\
\hline & Jumlah & 21 & $100 \%$
\end{tabular}

Sumber : Data Primer Tahun 2015

Berdasarkan hasil penelitian

menunjukkan bahwa hampir seluruh responden $(76 \%)$ memiliki tingkat kepatuhan dalam kategori patuh.
Hasil Analisis Hubungan pengetahuan penderita Hipertensi tentang hipertensi Terhadap Kepatuhan Reg imen Terapeutik

Hasil analisis menunjukkan $(p=0,039)$ sehingga Ho ditolak dan $\mathrm{H}_{1}$ diterima yang berarti terdapat hubungan antara pengetahuan penderita hipertensi tentang penyakit hipertensi dengan kepatuhan regimen terapeutik di kelurahan lirboyo RW 03 dan RW 08 Kota Kediri.

\section{Pembahasan}

Pada bagian ini akan di bahas mengenai hubungan tingkat pengetahuan pasien hipertensi tentang penyakit hipertensi dengan kepatuhan regimen terapeutik.

1. Tingkat pengetahuan pasien hipertensi tentang penyakit hipertensi

Tingkat pengetahuan pasien hipertensi tentang penyaki hipertensi didapatkan data hampir seluruhnya responden mempunyai pengetahuan baik yaitu $71 \%$

Hal ini dipengaruhi oleh informasi karena menurut hasil penelitian disebutkan bahwa sebagian besar responden 15 orang $(71 \%)$ memperoleh informasi sari petugas kesehatan berupa penyuluhan. Pengetahuan adalah hasil tahu dan ini terjadi setelah orang melakukan pengideraan melalui suatu objek tertentu. Penginderaan terjadi melalui panca indera manusia yakni: indera penglihatan, pendengaran, penciuman rasa dan raba. ebagian besar pengetahuan diperoleh melalui mata dan telinga ( Notoatmodjo, 2003: 127 )

Dari uraian diatas peneliti berpendapat bahwa pengetahuan seseorang diperoleh dari informasi karena dengan lebih sering seseorang memperoleh informasi yang didapat langsung tersimpan kedalam memori otak manusia juga bertambah(Nugroho, 2003). Sehingga ketika seseorang diberikan rangsangan yang berupa pertanyaan pertanyaan atau kuesioner, mereka hanya 
mengingat kembali (recoll) informasi yang tersimpan dimemori mereka.

\section{Kepatuhan Regimen Terapeutik}

Tingkat kepatuhan responden terhadap regimen terapeutik didapatkan data sebagian besar (76\%) responden patuh terhadap regimen terapeutik. Hal ini dipengaruhi oleh tingkat pendidikan responden ,Menurut Niven (2008) mengemukakan bahwa semakin tinggi pendidikan seseorang tingkat kematangan dan kekuatan seseorang akan lebih matang dalam berfikir. Meskipun Menurut Nugroho (2003) intelegensi seseorang akan menurun tepat sejalan dengan bertambahnya usia yaitu kemampuan menerima dan mengingat suatu pengetahuan yang tentunya berpengaruh terhadap pengetahuan yang didapat .

Dari uraian diatas dapat dijelaskan bahwa kepatuhan regimen terapeutik seseorang dipengaruhi oleh pendidikan. Semakin cukup pendidikan tingkat kematangan dan kekuatan seseorang akan lebih matang dalam berfikir serta menyadari betapa pentingnya mematuhi regimen terapeutik (Ramayulis,2008). yang dapat menurunkan resiko peningkatan tekanan darah karena mereka yakin bahwa dengan mematuhi regimen terapeutik akan membantu dalam proses penyembuhan dam menjaga kestabilan tekanan darah dalam tubuh (Palmer, 2007)

3. Hubungan Tingkat Pengetahuan Penderita Hipertensi Tentang Penyakit Hipertensi Dengan Kepatuhan Regimen Terapeutik Di Kelurahan Lirboyo RW 03 dan 08 Kota Kediri

Berdasarkan Uji Statistik didapatkan hasil dengan tingkat signifikan atau probabilitas $\mathrm{p}=0,039$ maka Ho ditolak sehingga dapat disimpulkan terdapat hubungan antara pengetahuan penderita hipertensi tentang penyakit hipertensi dengan kepatuhan regimen terapeutik, dengan koefisien korelasi 0,554 yang artinya terdapat hubungan yang substansial yaitu hubungan yang mendasari pada pengetahuan dengan kepatuhan regimen terapeutik begitu juga sebaliknya.

Dari hasil penelitian diketahui hampir seluruh responden berpengetahuan baik (71\%) tentang penyakit hipertensi. Lalu sebagian besar responden patuh terhdap regimen terapeutik (76\%). Pengetahuan merupakan hasil tau dan ini terjdi setelah orang melakukan pengineraan terhadap suatu objek tertentu( Widyasari, 2010). Penginderaan terjadi melalui panca indera manusia yakni : indera penglihatan, pendengaran, penciuman rasa dan raba. Sebagian besar pengetahuan manusia diperoleh dari mata dan telinga (Notoatmodjo, 2003). Salah sau faktor yang mempengaruhi pengetahuan adalah pendidikan. Pendidikan merupakan bimbingan yang diberikan oleh seseorang terhadap perkembangan orang lain menuju kearah suatu cita-cita tertentu (Niven,2008).

Jadi dapat dikatakan bahwa pendidikan itu menuntun manusia untuk berbuat dan mengisi kehidupanbnya untuk mencapai keselamatan dan kebahagiaan. Pendidikan diperlukan untuk mendapatkan informasi misalnya hal-hal yang menunjang kesehatan, sehingga dapat meningkatkan kualitas hidup(hawari,2003). Menurut Y. B Mantra yang dikutip oleh Notoatmodjo (1995) pendidikan dapat mempengaruhi seseorang termasuk juga perilaku seseorang akan pola hidup terutama dalam memotivasi untuk sikap berperan serta dalam pembangunan kesehatan. Makin tingi pendidikan seseorang makin mudah menerima informasi sehingga makin banyak pula pengetahuan yang dimiliki (agoes,2013). Dalam hal ini pengetahuan mempengaruhi kepatuhan seseorang dalam regimen terapeutik, kepatuhan adalah sifat patuh, ketaatan dan mau menjalani perintah yang diberikan kepadanya ( mardiyati, 2009). Dalam hal ini penderita mau mematuhi regimen terapeutik yang dianjurkan( utami,2009). 


\section{Kesimpulan}

1. Tingkat pengetahuan pasien hipertensi tentang penyakit hipertensi hampir seluruh responden (71\%) berpengetahuan baik.sebagian kecil responden berpengetahuan cukup (29\%). Tingkat pengetahuan yang baik dipengaruhi oleh informasi yang diperoleh dari petugas kesehatan berupa penyuluhan.

2. Kepatuhan regimen terapeutik di Kelurahan Lirboyo RW 07 dan 08 di Kota Kediri sebagian besar responden (76\%) Patuh terhadap regimen terapeutik, sebagian kecil responden (24\%) kurang mematuhi terhadap regimen terapeutik.

\section{Saran}

1. Bagi Profesi Keperawatan Diharapkan dapat mempertahankan tingkat kepatuhan regimen terapeutik dan bila perlu ditingkatkan dengan memberikan penyuluhan yang lebih intensif.

2. Bagi peneliti selanjutnya Penelitian ini dijadikan sebagai bahan untuk penelitian selanjutnya tentang faktorfaktor yang mempengaruhi regimen terapeutik.

3. Bagi Responden Perlu lebih meningkatkan lagi kepatuhan melakukan regimen tarapeutik secara optimal dirumah agar tidak terjadi kompikasi dari hipertensi.

4. Bagi Institusi Pendidikan Mempertahankan sistem pendidikian dan kurikulum yang ada dan bila perlu institusi memberikan pengapdian masyarakat dalam bentuk penyuluhan hipertensi.

\section{Daftar Pustaka}

Agoes, A dkk 2013, Hubungan Tingkat Pengetahuan tentang Faktor Resiko Hipertensi dengan Kejadian Hipertensi Pada Lansia di Dinoyo RW II Malang, diakses Juli 2013
Arikunto2010, Prosedur Penelirian Suatu Pendekatan Praktek, (Edisi revisi 2010), RinekaCipta, Jakarta

Dalimartha, Setiawan 2008, Care You Self Hipertensi, Penebar Plus,Jakarta

Ekarini, Diyah 2011. Faktor-Faktor yang Berhubungan dengan Tingkat Kepatuhan Klien Hipertensi dalam Menjalani Pengobatan di Puskesmas Gondangrejo Karanganyar, diakses selama tahun 2011

Fisher, NDL \& Gordon, HW 2005, Hypertensive Vascular Disease dalam Harrison's Principles of Internal Medicine 16thedition, Me Graw-Hill Profesional, USA

Gunawan, Lany 2004, Hipertensi Tekanan Darah Tinggi, Kanisius Media, Yogyakarta

Hawari, Dadang 2003, Manajemen Stres, Cemas, dan Depresi, Fakultas Kedokteran Universitas Indonesia,Jakarta

Hidayat, A 2007, Metode Penelitian dan Teknik Analisa Data, Salemba Medika, Jakarta

Mardiyati, Y 2009.Hubungan Tingkat Pengetahuan Penderita Hipertensi dengan Sikap Menjalani Diet Hiperte nsi di Puskesmas Ngawen 1 Kabupaten Gunung kidu IProvinsi D.I.Y, Universitas Muhamadiyah Surakarta

Megarani, AM 2007, Pada 2025 Seperlima Penduduk Indonesia Lansia,www.Tempointeraktif.com, Diakses tanggal 20 Oktober 2009

Murwani, A \& Wiwin, P 2010, Gerontik Konsep Dasar dan Asuhan Keperawatan Home Care dan 
Komunitas,

Fitramaya,

Yogyakarta

Niven 2008, Psikologi Kesehatan :Pengantar untuk Perawat dan Profesional, EGC, Jakarta

Notoatmojo, S 2005, Metodologi Penelitian Kesehatan, Edisi Revisi, Rineka Cipta, Jakarta

Notoatmojo, S2012. Promosi Kesehatandan Perilaku Kesehatan, PT. Rinek a Cipta, Jakarta

Nugroho, W 2003, Keperawatan Gerontik, EGC, Jakarta

Nursalam 2008, Konsep dan Penerapan Metodologi Penelitian Ilmu Keperawatan, Salemba Medika, Jakarta

Statistik, Indonesia 2010, http://www.datastatistikindonesia.com, Diakses tanggal 2 Oktober 2009

Sugiyono 2013, Metode Penelitian Kuantitatif Kualitatif Dan $R \& D$, Alfabeta, Bandung

Utami, Prapti 2009, Solusi Sehat Mengatasi Hipertensi, Agromedia Pustaka, Jakarta

Wawan, A \& Dewi, M 2011, Teori \& Pengukuran Pengetahuan, Sikap, dan Perilaku Manusia,Nuha Medika, Yogyakarta

Widyasari, DF \& Anika, C 2010, Pengaruh Pendidikan tentang Hipertensi

Terhadap Perubahan Pengetahuan dan Sikap Lansia di Desa Makamhaji Kartasura Sukoharjo,Diakses tanggal 20 Februari 2010 